\title{
Exploring Impression Management in an Organizational Setting
}

\author{
R. Venkatapathy* and V. Valarrmathi
}

Bharathiar School of Management and Entrepreneur Development, Bharathiar University, Coimbatore, Tamil Nadu, India; rvenkatapathy@rediffmail.com, valarrmathimba@gmail.com

\begin{abstract}
Impression management is the planned tendency of the individuals to behave in order to create and develop an image of themselves in the minds of others. Variety of IM tactics are expressed by employees to gain the attention of the superiors, co-workers and customers. The conceptualisation of impression management is gaining a positive attention among organizational researchers. This study is an attempt to probe the impression management tactics prevailing among banking professionals in the Indian context. Reliability co-efficient of the instrument is determined. Data obtained from 77 respondents through questionnaires is analysed and the results are revealed. Implications and future scope for research is discussed.
\end{abstract}

Keywords: Banking Professionals, Dimensions, Impression Management, Interpersonal Roles, Intimidation, Z Test

\section{Introduction}

Organizational behavior deals with the systematic study of the actions and attitudes that people illustrate within organizations [1]. As far as business world goes, every individual tries to positively impress in the best light possible. Quickening business world craves for smart workers who can create positive impression on their stakeholders. It is significant for individuals to regulate and control the impressions they create on themselves and on others. With everyday research increasing on teamwork, interpersonal roles, growing social interaction etc, significance on impression management is also gaining propulsion. In contemporary organizations, the role of impressions plays a predominant role. For e.g.:- Applicants try to create a positive impression on their job interview, salesman strives to impress the customers to make a sale, employees aim to positively impress their superiors to exhibit themselves to be top performers etc. Thus the importance of impression on different levels of employees across the organization draws attention on the manageability of these impressions.

\section{Impression Management}

Impression management is a deliberate proneness that people use to create a positive social image and identity [2]. It is effortful and requires cognitive resources. Goffman [3], coined the term impression management and from then on, sociologists and researchers have been adding thoughtfulness to the concept. Impression Management is a process where individuals seek to control or influence the expressions that others form on them. According to Sinha [4], Impression management is an active self-presentation of a person aiming to enhance his image in the eyes of others". It is a fundamental and universal process that involves number of influential factors. The concept of impression management has received the increasing levels of attention of organization scholars for the past 25 years. It is further evinced that behavioural characteristics play a significant and decisive role relating to performance excellence.

Impression Management has recently received increased positive attention. Because people are working in social interaction with each other [5] people depend on others,

${ }^{*}$ Author for correspondence 
try to influence each other, and attempt to create an impact on others, evaluate each other to make a decision, or just simply work together. All these are social processes that deal with different impression management tactics in an organizational setting.

Jones and Pittman [6] study was one of the first to highlight impression management tactics specifically in organizational setting. Bolino and Turnley [7] used and validated the taxonomy of IM tactics proposed by Jones and Pittman and they provided the IM scale which includes 25 items distinguished into five dimensions: Self-Promotion - Highlighting one's achievements in order to be viewed as competent employee. ("Make others aware of work activities"), Ingratiation - It is when one uses flattery to increase their likeability from other employees ("Do personal favours to people"), Exemplification - It is where individuals go above and beyond the call of duty to look dedicated ("People pretend to be busy even when they are not", Intimidation Individuals appear intimidating or threatening to have others view them as dangerous ("People shout at others to look powerful"), Supplication - People speak on their shortcomings and create a needy atmosphere on them ("Pretend to know something that you are familiar with").

\section{Research Question}

Do banking professionals differ on their scores on impression management?

\section{Null Hypothesis}

Ho1: Public and private sector respondents would remain homogenous on their scores on impression management.

Ho2: Male and Female respondents would remain homogenous on their scores on impression management.

Ho3: Rural and Urban respondents would remain homogenous on their scores on impression management.

\section{Instrumentation}

\subsection{Impression Management Scale}

Bolino \& Turnley [8] scale was adopted and modified. The scale consists of 25 positively worded items. Adequate care has been taken to modify each item in terms of rewording, rephrasing and simplifying the language. In our study, responses were collected using a four point scale (1-Strongly Disagree; 2- Disagree; 3-Agree; 4-Strongly Agree), such that higher scores indicate higher impression management and lower scores indicate lower impression management. The minimum possible score was 21 and maximum possible score was 84 . The scale has 5 dimensions namely, Self-Promotion with 6 items, Ingratiation with 5 items, Exemplification with 4 items, Intimidation with 5 items and Supplication with 5 items.

\subsection{Reliability}

The Cronbach's alpha for the overall scale was found to be 0.801. Spearman Brown split half reliability formula was used to find the reliability of dimensions. The scores were Self-promotion - 0.734; Ingratiation - 0.719, Intimidation - 0.767, Supplication - 0.726. Pilot study indicated low reliability on exemplification dimension and therefore it was removed.

\section{Sample and Sample Characteristic}

Samples for the current study have been carefully chosen after in-depth analysis of fields that function with impression management. Simple Random technique was used. Banking professionals from both public and private sector in Coimbatore was considered for the study. Questionnaires were collected from 95 respondents. On scrutinizing, 18 questionnaires were not marked properly and were incomplete. Thus, 77 questionnaires (41-Public; 36-Private) were found usable.

\section{Analysis of Data}

Statistical analysis was conducted on the collected data. The mean difference test by using $\mathrm{z}$-test was carried out to find the score of impression management among the public and private sector banking professionals.

\subsection{Interpretation of Data}

Table1 reveals the mean, standard deviation and the mean difference scores on impression management. $\mathrm{z}$ test revealed that there exists no significant difference among the public sector and private sector banking employees on all dimensions except for intimidation. Intimidation is a process where the employee exhibits that he is powerful and maintains a closer relationship with the top management in order to gain the attention of his co-workers. The scores on all other dimensions - Self-promotion, Ingratiation and Supplication were all found to be homogenous on both public and private 
Table 1. Z-test: Dimension-wise analysis

\begin{tabular}{|c|c|c|c|c|c|c|}
\hline Dimensions & Sector & $\mathrm{N}$ & Mean & $\begin{array}{c}\text { Std. } \\
\text { Deviation }\end{array}$ & $\begin{array}{c}\text { Sig. } \\
\text { (2-tailed) }\end{array}$ & $\begin{array}{c}\text { Mean } \\
\text { Diff }\end{array}$ \\
\hline $\begin{array}{c}\text { Self- } \\
\text { promotion }\end{array}$ & Private & 36 & 18.63 & 2.28 & 0.63 & 0.29 \\
\hline \multirow{2}{*}{ Ingratiation } & Private & 36 & 15.16 & 2.19 & \multirow{2}{*}{0.47} & \multirow{2}{*}{0.38} \\
\hline & Public & 41 & 14.78 & 2.43 & & \\
\hline Intimidation & Public & 41 & 10.97 & 2.81 & $0.00^{*}$ & 2.60 \\
\hline \multirow{2}{*}{ Supplication } & Private & 36 & 13.94 & 3.07 & \multirow{2}{*}{0.29} & \multirow{2}{*}{0.70} \\
\hline & Public & 41 & 13.24 & 2.76 & & \\
\hline
\end{tabular}

Source: Compiled from primary data. *Significant at $5 \%$ level

Table 2. Z-test: Gender-wise analysis

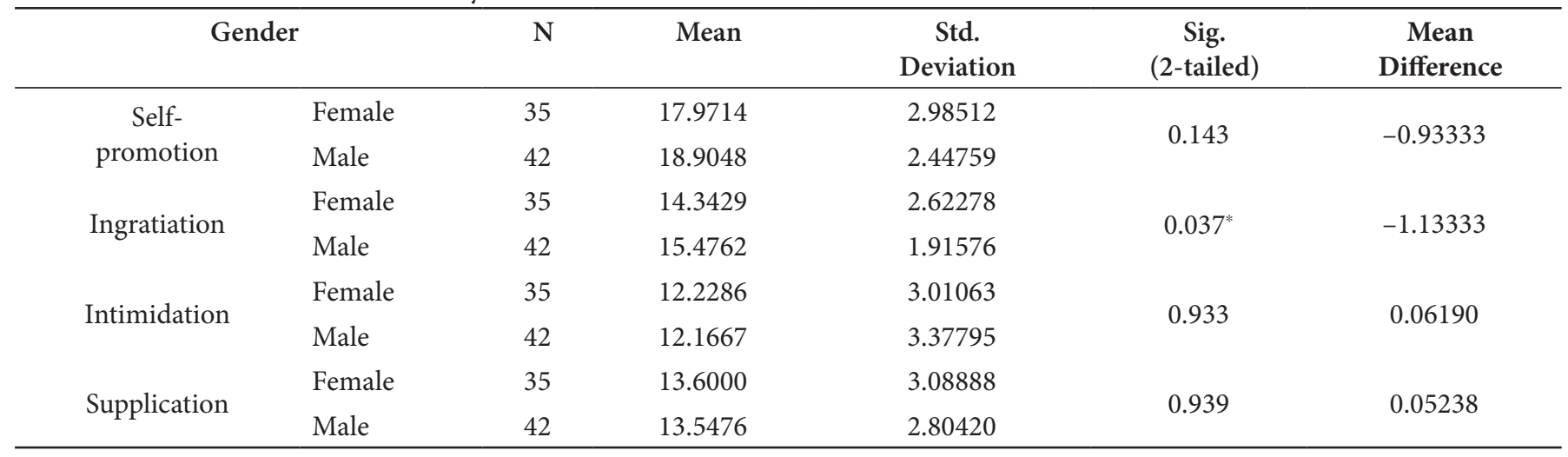

Source: Compiled from primary data. "Significant at $5 \%$ level

sector banking professionals. The results reveal that employees from private banks score high on their intimidation compared to public sector banks.

The inference could be that private sector employees suffer from job insecurity reasons and therefore they project themselves to be closer to management and behave aggressive. Previous researches suggest that people who successfully use intimidation are seen as forceful and aggressive. They may be seen as socially undesirable in their workplace [6]. Also employees perceive that intimidation will increase their job performance, but use of such impression may have a deleterious resultance on interpersonal relationship among their co-workers.

Table 2 reveals the mean, standard deviation and the mean difference scores on impression management of male and female respondents. It reveals that there is no significant difference exists between male and female groups in all the dimensions of impression management except ingratiation. Male employees posed a higher mean score on ingratiation compared to female respondents. It could be interpreted that male in order to exhibit them to be closer to top management they do personal favours for their superiors, take interest in colleagues personal life. Results reveal that male respondents involve in activities complimenting their colleagues and superiors to be seen as likeable by others. The need for job is high among Indian male, anyhow there is no much difference in the mean score of male and female respondents. It may be high because male employees usually aspire to project themselves to be friendly in a work environment. Showing this IM Tactic will help the male workers to let their strength and talents aid to achieve future opportunities and career advancements.

Table 3 reveals the mean, standard deviation and mean difference between rural and urban respondents of the study. It shows Intimidation - the tendency to show power among colleagues is high among employees hailing from rural background. Employees showing the intimidation tactic of impression management appear and wish to appear as threatening among their co-workers in their workplace. This will project a negative impression to their superiors. People hailing from rural background may still be unaware 
Table 3. Z-test: Rural vs. urban-wise analysis

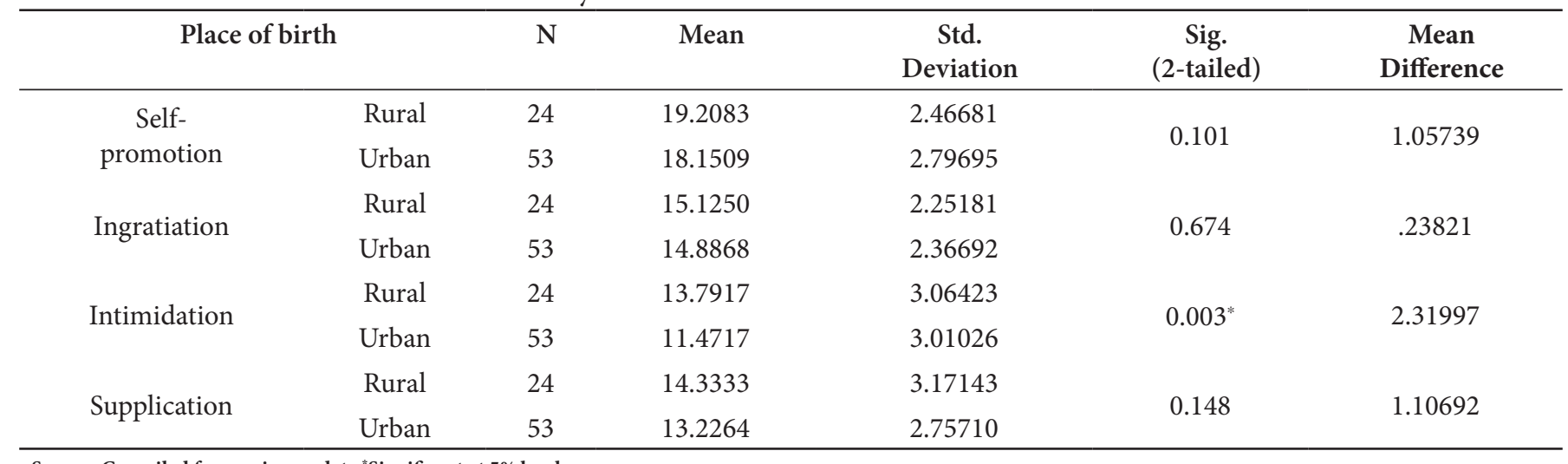

Source: Compiled from primary data *Significant at $5 \%$ level

of the significance of interpersonal relationship in their workplace, which may be the reason for their higher score on intimidation tactic.

\section{Conclusion}

Private sector bank employees exhibit intimidation tactic compared to public sector banks. Male employees show the tendency towards doing personal favours to their co-workers in comparison with female employees. Respondents from rural background score high on intimidation compared to urban respondents. This is a finding for the practicing managers to understand the potential influence of impression management tactics in workplace. The results of the study provide potential directions for future research as well. Specifically, these findings have shown that people adopt impression management tactics in order to create a positive image on them. These tactics may help the employee to work more or less in any environment. The results clearly stress the need for interpersonal skills to be developed among employees hailing from rural background. Female employees should also be trained to develop friendly work atmosphere, thereby creating good positive impression among themselves. Additional research is required to develop a clearer understanding on whether impression management behaviours actually impact their work excellence or other extra role performance. Future research could be based on the variables such as empowerment, employee wellbeing etc that will be helpful to manage the impressions of employees.

\section{References}

1. Robbins S.P., Odendaal A., Roodt G., Organisational Behaviour: Global and Southern African Perspectives, South Africa: Pearson, 2003, pp. 7.

2. Zerbe W.J., Paulhus D.L., "Socially desirable responding in organisational behaviour : a reconception", Acad. Manag. Rev., vol. 12(2), pp.250-264, 1987.

3. Goffman E., The Presentation of Self in Every Day Life (1959), Chapter in Part I, Ed. Book, "Contemporary Sociological Theory”, John Wiley and Sons Ltd., 2012, pp. 46-61.

4. Sinha J.B., Culture and Organisational Behaviour, India: SAGE Publications, India, 2009, pp. 104.

5. Schlenker B.R., Impression Management: The Self Concept, Social Identity, and Interpersonal Relations, Brooks/Cole Publishing Company, 1980, pp. 1-30.

6. Jones E.E., Pittman T.S. Toward a general theory of strategic selfpresentation, J. Suls, Ed. Book, "Psychological perspectives on the self”, Hillsdale, NJ: Lawrence Erlbaum, pp. 231-261, 1982.

7. Bolino M.C., Turnley W.H., "Measuring impression management in organisations: a scale development based on the Jones and Pittman Taxonomy-1982", Organisational Research Methods, vol. 2(2), pp. 187-206, 1999.

8. Bolino M.C., Kacmar K.M., Turnley W.H., Gilstrap J.B., "A multi-level review of impression management motives and behaviours", J. Manag., vol. 34(6), pp. 1080-1109, 2008. 